\title{
Imagens do Pensamento em Gilles Deleuze: REPRESENTAÇÃO E CRIAÇÃO
}

\author{
Eduardo Mauricio $\star$ \\ Mauricio Mangueira $\star \star$
}

\begin{abstract}
Resumo
Um dos principais objetivos da filosofia de Gilles Deleuze foi restituir ao pensamento sua potência criadora, que se encontrava sufocada pela hegemonia da perspectiva representacional. Combatendo a ideia de que pensar é uma atividade voluntária, reflexiva e universal, o filósofo francês explicita, em Proust e os signos, de que modo o ato de pensar encontra-se relacionado a um procedimento inventivo. Efetuando uma completa modificação nos principais conceitos do modelo da representação, tais como os conceitos de signo, essência e verdade, Deleuze nos mostra que se o pensamento diz respeito a algo, é, sobretudo, à afirmação de um estilo criador.
\end{abstract}

Palavras-chave: Gilles Deleuze; pensamento; representação; criação.

\section{Images of Thought in Gilles Deleuze: REPRESENTATION AND CREATION}

\begin{abstract}
One of the major goals of Gilles Deleuze's philosophy was restitute thinking its creative power, apower that was smothered by the hegemony of the representational perspective. Combating the idea that thinking is simply a voluntary, reflective and universal activity, the French philosopher explains in Proust and Signs how the act of thinking is related to an inventive procedure. Performing a radical change in the main concepts of the representational model, such as the concepts of sign, essence and truth, Deleuze shows that if thinking is related to something, it is primarily to the affirmation of a creative style.

Keywords: Gilles Deleuze; thinking; representation; creation.

\footnotetext{
^ Graduação em Psicologia. Universidade Federal de Sergipe, Brasil.

E-mail: edu.mauricio@bol.com.br

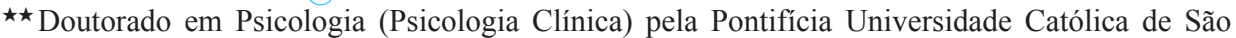
Paulo. Atualmente é professor associado II da Universidade Federal de Sergipe. Endereço: Universidade Federal de Sergipe, Centro de Educação de Ciências Humanas, Departamento de Psicologia. Jardim Rosa Elze, Rosa Elze, 49100-000 - Sao Cristóvão, SE - Brasil.

E-mail: mauriciomangueira@infonet.com.br
} 


\section{INTRODUÇão}

Poderíamos dizer que um dos temas mais importantes da filosofia de Gilles Deleuze é o pensamento. Desde suas obras iniciais, passando por seus textos que tratam de literatura, cinema ou pintura e até mesmo nos trabalhos desenvolvidos em conjunto com Félix Guattari, a problematização acerca do pensamento, ou melhor, acerca das imagens do pensamento sempre se fez presente.

Deleuze considera que um pensamento possui certas coordenadas ou eixos de orientação que permitem associá-lo a um determinado modo de funcionamento. Isto significa dizer que essas coordenadas originam imagens do que seria o pensamento, sua natureza ou finalidade. O privilégio atribuído a esta problemática tinha como motivo principal o fato de que para Deleuze essas imagens forneceriam de antemão uma determinada concepção do pensamento, orientando não somente o pensar, mas também a produção do conhecimento nos mais diversos domínios como a ciência, a arte e, principalmente, a filosofia. Uma imagem seria então um conjunto de coordenadas que não somente orientariam um pensamento, mas que norteariam também as suas possibilidades de criação. ${ }^{1}$

É importante observar que, do ponto de vista de Deleuze, uma determinada imagem do pensamento tem predominado na cultura ocidental, imagem que ele denominará de moral. Esta imagem moral possui algumas relações com aquilo que o filósofo francês denominará de pensamento representacional ou modelo da representação, como veremos num primeiro momento. No entanto, se Deleuze (2006) se preocupa em evidenciar as características do modelo da representação, dessa imagem moral do pensamento, é para evidenciar outra imagem presente em filósofos e literatos, cuja característica fundamental é não o reconhecimento das essências, mas constituir-se enquanto potência criadora. É o que veremos num segundo movimento analisando sua leitura de Marcel Proust, na obra Proust e os signos.

A importância de Proust e os signos no percurso de Deleuze é que esta obra permite ao filósofo francês destituir alguns dos principais pressupostos da imagem representacional do pensamento, se utilizando para isso dos mesmos conceitos observados no modelo da representação. A obra de Proust, notadamente Em Busca do Tempo Perdido (2001), possibilita ao filósofo operar uma completa transformação em conceitos tais como signo, essência e verdade. São justamente estas novas significações que permitirão ao filósofo francês deslocar certos conceitos, modificá-los de tal forma que eles assumam um aspecto totalmente diferente do sistema filosófico de onde foram colhidos. Este procedimento utilizado por Deleuze constitui um dos traços característicos de sua filosofia. Em sua perspectiva, o trabalho do filósofo se traduz essencialmente por uma criação de conceitos: a seu ver, é isto que diferenciaria a filosofia de outros ramos do conhecimento, tais como as artes - que se caracterizam por uma produção de agregados sensíveis - e as ciências - caracterizadas por uma produção de funções. ${ }^{2}$ Mas, criar conceitos não significa necessariamente inventar novos termos. Esta produção diz respeito também às reorientações de conceitos já existentes, de forma 
tal que eles adquiram uma potência até então desconhecida quando transportados de seu sistema filosófico original. O próprio Deleuze (2009a, p. 17) nos diz em Diferença e repetição:

Um livro de filosofia deve ser, por um lado, um tipo muito particular de romance policial e, por outro, uma espécie de fiç̧ão científica. Por romance policial, queremos dizer que os conceitos devem intervir, com uma zona de presença, para resolver uma situação local. Modificam-se com os problemas. Eles têm esferas de influência em que, como veremos, se exercem em relação a "dramas" e por meio de uma certa "crueldade". Devem ter uma coerência entre si, mas tal coerência não deve vir deles. Devem receber sua coerência de outro lugar.

Como veremos ao longo deste artigo, é esta produção ou modificação de conceitos que Deleuze nos mostra de maneira brilhante em seu Proust e os signos. Antes, no entanto, apontaremos algumas características do pensar representacional, pois é frente a ele que as análises do pensador francês adquirem certa inteligibilidade.

\section{O MODELO DA REPRESENTAÇÃO}

Em muitos de seus trabalhos, Deleuze denuncia as principais características do modelo da representação, ${ }^{3}$ tais como o senso comum, com seu correlato recognição, e/ou o comprometimento do pensamento com a busca de verdades universais e atemporais. Para ele o senso comum seria responsável por construir uma imagem do pensamento - o pensamento dogmático -, na qual este se apresenta como naturalmente propenso ao conhecimento. Ou seja, o senso comum se encarregaria de construir uma representação universalizante do que seria o pensamento.

Esta representação universal está fundada em um pressuposto no qual o pensador, de antemão, possui uma "boa vontade" de conhecer as coisas, sendo que esta boa vontade é precisamente aquilo que lhe garantiria um exercício natural do pensamento. Quando o filósofo francês faz menção a um exercício natural do pensamento, está se referindo à crença de que este possui como característica principal uma propensão a buscar o verdadeiro. A principal consequência da ação do senso comum na filosofia seria então a construção deste modelo em que pensamento e verdade se encontram profundamente relacionados.

Além desse pressuposto contido no senso comum, outra importante característica observada na imagem dogmática do pensamento é a recognição ou o modelo da recognição. Este modelo tem como função principal afirmar que conhecer é, na verdade, reconhecer, sendo que este reconhecimento dos objetos e do mundo em geral exige um uso congruente das faculdades, em que cada uma delas transmite às outras uma identidade do objeto a ser conhecido ou re-conhecido. 
Assim, através da recognição, o pensamento - representacional - se caracterizará por tecer com o mundo uma relação que tem por objetivo principal reconhecê-lo, ou seja, uma relação puramente contemplativa. Esta contemplação seria feita por um pensador que se apoiaria em valores transcendentes universais, buscando atingir a verdadeira natureza das coisas, sua identidade, sua essência. Desse modo, a recognição nos permitirá atingir o elemento principal do modelo da representação para Deleuze: a identidade. Logo, encontramos em Diferença e repetição (DELEUZE, 2009a, p. 15): "O primado da identidade, seja qual for a maneira pela qual esta é concebida, define o mundo da representação". Isto significa dizer que, nesta imagem do pensamento, conhecer nada mais é do que reconhecer aquilo que permanece idêntico a si mesmo ao longo do tempo e espaço. ${ }^{4}$

Devemos ressaltar que, da perspectiva do filósofo francês, essa imagem representacional do pensamento possui uma origem: a filosofia platônica. No seu texto "Platão e o simulacro" (DELEUZE, 2007a) ele desenvolve de forma clara essa tese.

Nesse texto, Deleuze começa sua exposição fazendo referência à conhecida distinção platônica entre o mundo das ideias ou essências e o mundo das aparências. Entretanto, ele apontará que esta distinção na verdade se apresenta como pano de fundo para outra, ainda mais importante, que serve de base a toda a filosofia platônica, e que posteriormente acabará se constituindo em um modelo para toda a filosofia ocidental: a separação entre dois tipos de cópias, a verdadeira e a falsa. Ou antes, a cópia e o simulacro.

O objetivo principal da filosofia platônica seria então selecionar pretendentes. Deleuze nos aponta, assim, os vínculos da filosofia platônica com a política e a moral, já que a questão fundamental, no platonismo, diz respeito a como distinguir os verdadeiros dos falsos candidatos, ou seja, como selecionar aqueles que conservam uma correlação com a coisa mesma ou essência, e os que não possuem tal atributo. Sabemos que o conceito de essência, no platonismo, guarda uma estreita correlação com o conceito de identidade: a essência é aquilo que é idêntica a si própria, por isso ela é o modelo original, primeiro.

Sendo assim, os candidatos que possuírem uma correspondência com a essência serão considerados boas cópias. Já aqueles que não possuírem esta correlação serão considerados más cópias ou simulacros. Por isso, a cópia será dita boa quando ela representar a identidade ideal. Este é o mundo da representação em geral: representar nada mais é do que "copiar" a essência, buscar a identidade das coisas.

Através de "Platão e o simulacro" podemos perceber a importância da articulação entre os conceitos de identidade e de cópia para o pensamento representacional. Se tomarmos separadamente o conceito de identidade, corremos o risco de permanecer naquilo que Deleuze denomina de "distinção manifesta" do platonismo: a distinção entre o mundo das essências (aquilo que permanece idêntico a si mesmo ao longo do tempo) e o mundo das aparências. Entretanto, ao correlacionarmos os conceitos de identidade e de cópia, atingimos o âmago da filosofia da representação, que diz respeito à reprodução de um modelo, mas não 
de qualquer modelo, e sim do modelo verdadeiro, já que idêntico a si próprio. A cópia só será dita boa na medida em que conseguir reproduzir esse modelo ou, em outras palavras, reproduzir a verdade. Evidencia-se, assim, por que Deleuze considera a filosofia platônica como a origem do pensamento representacional, pois na leitura que faz das ideias do filósofo grego, nela encontra todos os elementos que constituem o modelo da representação: a identidade existente entre a cópia e o modelo a ser copiado; a imagem moral calcada no senso comum (o modelo é verdadeiro, pois idêntico a si próprio); e o exercício de recognição (reconhecer aquilo que permanece idêntico a si próprio, ou seja, reconhecer a verdade).

\section{Proust e a Gênese do ato de pensar}

Se Deleuze se preocupa em traçar uma crítica ao modelo da representação e à imagem moral do pensamento é porque para ele pensar não está correlacionado apenas ao exercício de recognição. A recognição é somente uma das ocupações do pensamento, mas não significa que esta seja a sua principal tarefa.

Da perspectiva do filósofo francês, a característica fundamental do pensamento é que ele pode se constituir em uma potência criadora que se realiza no ato de pensar. Poderíamos facilmente achar que os dois termos - pensamento e ato de pensar - comportam o mesmo sentido, sendo assim perfeitamente intercambiáveis. Mas, para Deleuze, existe uma diferença essencial entre os dois conceitos, pois a palavra ato traduz uma ação: uma ação de pensar. É por isto que enquanto o pensamento se encontra relacionado ao modelo da recognição, ou seja, uma atividade puramente contemplativa, $o$ ato de pensar se encontra relacionado à criação, ou seja, uma ação. Encontramos novamente em Diferença e repetição (DELEUZE, 2009, p. 203):

O que é primeiro no pensamento é o arrombamento, a violência, é o inimigo, e nada supõe a Filosofia; tudo parte de uma misosofia. Não contemos com o pensamento para fundar a necessidade relativa do que ele pensa; contemos, ao contrário, com a contingência de um encontro com aquilo que força a pensar, a fim de erguer e estabelecer a necessidade absoluta de um ato de pensar, de uma paixão de pensar. As condições de uma verdadeira crítica e de uma verdadeira criação são as mesmas: destruição da imagem de um pensamento que pressupõe a si próprio, gênese do ato de pensar no próprio pensamento.

Se prestarmos atenção no trecho destacado acima, veremos que Deleuze fala da "contingência de um encontro com aquilo que força a pensar" e em uma "gênese do ato de pensar no próprio pensamento". Percebemos, então, que o ato de pensar é gerado, provocado no pensamento quando este é violentado por alguma coisa. Esta coisa é o que o filósofo denominará de signo. Na obra denominada Proust e os signos (DELEUZE, 2006), lançada quatro anos antes de Diferença e repetição (DELEUZE, 2009a), Deleuze já mostrava a importância do conceito de signo no combate ao modelo da representação. 
Quando anteriormente tratamos da questão do pensamento, vimos como este se apoiava em alguns pressupostos fornecidos pelo senso comum. Estes pressupostos eram responsáveis por construir uma imagem do pensamento onde o mesmo era dotado de uma natureza reta, espontaneamente predisposta ao conhecimento da verdade. Mas não é só isso: o senso comum erigia também a imagem de um pensador caracterizado por uma boa vontade para conhecer.

Para Deleuze, a importância da obra de Proust reside no fato de que ela constitui uma nova imagem do pensamento ou mais ainda um pensamento sem imagem, isto é, um pensamento destituído dos pressupostos. Proust vai demonstrar, através de sua literatura, que a busca da verdade nunca implica uma decisão consciente por parte do pensador e muito menos um exercício natural do pensamento baseado na colaboração de todas as suas faculdades.

A Recherche é, antes de tudo, uma busca da verdade, em que se manifesta toda a dimensão "filosófica" da obra de Proust, em rivalidade com a filosofia. Proust constrói uma imagem do pensamento que se opõe à da filosofia, combatendo o que há de mais essencial numa filosofia clássica de tipo racionalista: seus pressupostos. O filósofo pressupõe de bom grado que o espírito como espírito, o pensador como pensador quer o verdadeiro, ama ou deseja o que é verdadeiro, procura naturalmente o verdadeiro. Ele antecipadamente se confere uma boa vontade de pensar: toda a sua busca é baseada numa “decisão premeditada” (DELEUZE, 2006, p. 88).

A chave para a compreensão da crítica que é feita ao modelo do pensamento representacional se encontra na expressão "decisão premeditada". A verdade não é algo que se possa atingir de forma voluntária, ao contrário, ela é objeto de um aprendizado sempre involuntário. Esta é a sua característica principal. Deleuze vai mostrar como em toda a obra de Proust o personagem principal vai descobrindo, pouco a pouco, por meio de um lento aprendizado, coisas que se mostravam obscuras no início de seu percurso.

É isso que distinguirá essa verdade, que tem como traço principal ser fruto de um longo aprendizado, das verdades filosóficas do senso comum. Estas últimas são verdades atingidas pelo pensamento representacional. Desta forma, elas se mantêm abstratas ou gerais. Já vimos que uma das principais características do pensamento representacional é justamente se esforçar por descobrir verdades universais.

Por outro lado, as verdades decorrentes de um aprendizado advindo de encontros carregam consigo um sinal que lhes confere vigor: a autenticidade. Este sinal é exatamente a sua involuntariedade. Por chegarem de forma involuntária essas verdades se constituem na objetivação e subjetivação provindas de um encontro ao qual não se pode furtar. Elas atingem os sujeitos independentemente da sua vontade e por isso os violentam. Esta é a sua marca fundamental: a coação que elas exercem sobre o pensador. 
Percebemos, então, que o pensamento só é capaz de atingir as verdades voluntárias, decorrentes de seu exercício calcado na recognição. Para conseguir alcançar outro modo de funcionamento, o sujeito pensante deve ser alvo de uma verdadeira coerção provocada por um encontro involuntário com algo que o violente. Este algo, como já dissemos, é o que Deleuze chamará de signo. É o signo que permitirá estabelecer a diferença entre o pensamento e o ato de pensar. E se o conceito de signo assumiu, ao longo da história, um papel essencialmente representacional, aqui esse conceito adquirirá características completamente diferentes. ${ }^{5}$

A principal distinção entre o pensamento e o ato de pensar se encontra no fato de que o último é gerado no pensamento, quando do encontro deste com os signos. O signo é aquilo que consegue retirar do pensamento o seu caráter abstrato, baseado nos modelos do senso comum e da recognição. Através da violência provocada pelos signos, o pensamento se vê confrontado com um de seus pressupostos fundamentais: a sua suposta predisposição a pensar.

O signo deixa claro que entre o ato de pensar e o pensamento não existe nenhuma relação intrínseca. Ao contrário, se o pensamento possui afinidade com algo é somente com a recognição. Daí a sua impotência diante do signo já que este impede seu exercício de recognição baseado no acordo entre as faculdades. Por isso Deleuze vai dizer que o ato de pensar gerado pelos signos é a real possibilidade de criação.

O que nos força a pensar é o signo. O signo é o objeto de um encontro; mas é precisamente a contingência do encontro que garante a necessidade daquilo que ele faz pensar. $\mathrm{O}$ ato de pensar não decorre de uma simples possibilidade natural, é, ao contrário, a única criação verdadeira. A criação é a gênese do ato de pensar no próprio pensamento. Ora, essa gênese implica alguma coisa que violente o pensamento, que o tira de seu natural estupor, de suas possibilidades apenas abstratas (DELEUZE, 2006, p. 91).

Quando colocamos que o signo impede o exercício de recognição calcado no acordo entre as faculdades, devemos lembrar que a principal característica da recognição é justamente fazer todas as faculdades trabalharem sob a perspectiva de um objeto comum que era dado a reconhecer. $\mathrm{O}$ ato de pensar, por seu lado, implica um diferente funcionamento das faculdades. Por ser ele o resultado de uma violência imposta pelos signos ao pensamento, não será possível que as faculdades trabalhem de forma voluntária, ou seja, elas não podem se antecipar em sua tarefa de reconhecer os objetos. O encontro involuntário acarreta, por sua vez, um exercício involuntário das faculdades: aqui, cada uma somente transmitirá às demais a agressão desse encontro.

Dissemos anteriormente que um dos objetivos de Deleuze em Proust e os signos era ressaltar a importância do conceito de signo no combate ao modelo da representação. Sendo assim, devemos nos deter de forma mais minuciosa a uma afirmação de Deleuze citada anteriormente: o ato de pensar é a única criação verdadeira. 
Já sabemos que o que está na base do ato de pensar é o signo. É ele quem gera o ato de pensar através de seu encontro fortuito com o pensamento. Desse modo, em sua análise desenvolvida sobre a obra de Proust, Deleuze irá considerar Em busca do tempo perdido como um sistema plural constituído por várias espécies de signos. De início, o que importa saber é que cada espécie de signo possui características próprias que a distinguem umas das outras. Em verdade, se ainda não podemos definir o que é um signo, podemos dizer ao menos que eles são portadores de mundos particulares que serão vivenciados pelo sujeito.

Se os signos são portadores de mundos específicos, isto significa dizer que um determinado sistema de signos possui códigos específicos, leis particulares. ${ }^{6}$ E se $o$ ato de pensar decorre do encontro do pensamento com os signos, podemos perceber que este ato encontrar-se-á invariavelmente implicado em um mundo ou mundos específicos dos quais o sujeito faz parte no momento do encontro.

É por isso que o ato de pensar, ao contrário do pensamento, é sempre parcial. Enquanto as verdades do pensamento tinham por pretensão a universalidade, as verdades atingidas pelo ato de pensar são verdades implicadas, comprometidas com um determinado mundo emissor de signos particulares. Mas não é só isso. As verdades implicadas possuem como traço essencial justamente seu caráter involuntário: elas são objeto de um aprendizado particular que não depende da vontade.

Esse aprendizado involuntário diz respeito à interpretação dos diferentes tipos de signos que se encontram pelo caminho. O aprendizado concerne essencialmente a isto: à interpretação de signos. $\mathrm{O}$ ato de pensar é a forma através da qual o sujeito interpreta os diferentes tipos de signos que o violentam em seu percurso. E, como já vimos, o ato de pensar é parcial, implicado. Como poderia ser de outra forma já que ele decorre de encontros involuntários com signos experimentados por cada indivíduo em seu próprio trajeto?

A criação é a forma através da qual se decifra os signos, ou seja, é a forma através da qual se aprende. E se Deleuze nos diz que o ato de pensar é a única criação verdadeira, é porque na tarefa de interpretar os diferentes tipos de signos ninguém pode ajudar. $\mathrm{O}$ aprendizado é sempre particular e involuntário, por isso ele é a única criação real. Aqui não existe uma identidade a ser buscada de forma voluntária por um pensamento que tem por função principal a recognição. Por meio de sua violência, os signos arruinam o modelo da recognição contido no pensamento. Ao ato de pensar só resta a criação: esta se constitui agora como sina.

Devemos ressaltar, entretanto, que esse trabalho de criação ou interpretação dos diferentes tipos de signos tece uma relação privilegiada com o tempo. Essa relação se encontra expressa não somente por todo o romance, mas até mesmo nos próprios títulos e subtítulos da obra como, por exemplo, tempo perdido e tempo recuperado. Em busca do tempo perdido apresenta, na verdade, uma concepção plural do tempo que se contrapõe a uma concepção puramente cronológica do mesmo. Proust será,inclusive, de fundamental importância para Deleuze, haja vista o desenvolvimento de sua própria perspectiva teórica acerca do tempo, perspectiva observada não apenas em Proust e os signos, mas no decorrer da obra do filósofo francês. 
Da mesma forma que Proust e os signos nos apresenta quatro tipos de signos - mundanos, amorosos, sensíveis e artísticos -, observamos igualmente, na obra, quatro linhas ou variações do tempo. São elas: tempo perdido, tempo que se perde, tempo que se redescobre e tempo absoluto ou original. A questão é que a cada tipo de signo corresponde uma linha privilegiada de tempo. Na verdade, cada tipo de signo participa mais ou menos de todas as linhas do tempo. Por exemplo, os signos mundanos participam mais ativamente de um tempo que se perde: por serem signos frívolos, vazios, eles denotam um tempo que o personagem "esperdiça" em seu percurso.

No entanto, os signos mundanos, assim como todos os outros, possuem suas verdades, e por isso são essenciais no trajeto da personagem. É aqui neste ponto que as obras de Proust e de Deleuze convergem de forma magistral, pois por meio da obra de Proust, Deleuze atesta aquilo que o escritor francês já havia mostrado com perfeição: que toda e qualquer verdade é uma verdade do tempo. Ao contrário do pensamento representacional que buscava verdades eternas ou atemporais, Proust e Deleuze nos apresentam outra relação possível entre o pensamento, o tempo e a verdade.

Além disso, em Proust e os signos observamos certo privilégio dos signos artísticos em relação aos demais, já que eles são os signos capazes de revelar a essência do artista. Isto também se verifica em relação às linhas do tempo: o tempo absoluto - por ser o tempo do qual os signos artísticos mais participam ativamente - também possui certo privilégio em relação às outras linhas do tempo. Mas, se cada signo participa mais ou menos de todas as linhas do tempo, é justamente porque cada linha reage sobre as demais, revelando verdades que não seriam acessíveis ao artista caso o aprendizado não envolvesse todos os signos. Desse modo, os outros signos possuem importância na medida em que eles conduzem o artista, passo a passo, aos signos da arte. Isto somente se torna possível porque cada signo mobiliza diferentes faculdades, a exemplo da inteligência, percepção e, principalmente, a memória, seja esta última voluntária ou involuntária. E se existe certa hierarquia dos signos, essa hierarquia se explica não somente pelas linhas do tempo, como também pela faculdade que os interpreta.

No caso dos signos mundanos, podemos notar um privilégio da percepção e da inteligência, já que é por meio delas que o personagem compreende as constantes modificações e alterações que caracterizam a vida social, o tempo que se perde. Já no que diz respeito aos signos amorosos, é a memória voluntária quem participa mais ativamente de sua interpretação. Deleuze cita brilhantemente o exemplo do amante que recorre constantemente à memória, na tentativa de captar signos que atestem as possíveis mentiras do amado. A memória involuntária, por sua vez, é a principal faculdade de interpretação dos signos sensíveis. Por vezes, no percurso do personagem, um determinado objeto libera alguma qualidade sensível - um odor, por exemplo - que o lança involuntariamente a um passado que se conserva em si mesmo e do qual o personagem não possuía mais recordação alguma, ao contrário de um passado que se conserva na lembrança, como no caso dos signos amorosos. 
Finalmente, no caso dos signos da arte, é o próprio pensamento que é mobilizado na forma de um ato de pensar, isto é, na forma de um procedimento inventivo ou criador. E se o pensamento possui certo privilégio em relação às demais faculdades no trabalho de interpretação é porque por meio dele se é possível atingir um tempo absoluto, tempo "complicado" que contém todos os outros, que reage sobre todos os demais, revelando as verdades dos signos mundanos, amorosos e sensíveis, verdades até então desconhecidas pelo artista que, no momento em que sofria a ação desses signos, acreditava estar simplesmente "perdendo tempo".

Torna-se necessário, contudo, explicitar o que Deleuze considera por traduzir ou interpretar um signo e o porque dessa interpretação implicar, necessariamente, uma criação. Para investigar melhor a afirmação do filósofo francês, nos deteremos a dois outros conceitos que possuem uma estreita correlação com o conceito de signo: o sentido e a essência.

Em Proust e os signos, Deleuze nos mostra que todo signo possui um sentido que necessita ser descoberto, decifrado. Dizer que o sentido se encontra enrolado, implicado no signo, não significa dizer que ele já exista previamente. Ele é produzido pelo ato de pensar quando este sofre a violência dos signos. Descobrir o sentido de um signo não é então desvelar algo já existente. A interpretação de um signo é inseparável de um movimento de criação. Daí a afirmação do filósofo vista anteriormente de que a tradução de um signo é a mais pura forma de criação.

O conceito de essência surgirá então para marcar esse envolvimento do signo com o seu sentido. Assim, todo signo possui também uma essência, que pode ser atingida por meio da descoberta de seu sentido. Apesar dos dois conceitos parecerem significar, à primeira vista, a mesma coisa, o filósofo francês deixa claro em várias passagens da obra que a essência não se reduz ao sentido, parcialmente dependente do sujeito, ou muito menos ao próprio signo em si, parcialmente dependente de um objeto.

Isso significa dizer que a essência, tal como o sentido, também é produzida, mas de uma forma completamente diferente. É mais fácil perceber por que Deleuze nos diz que o sentido depende parcialmente das associações subjetivas desenvolvidas pelo sujeito quando do encontro deste com os signos. Como já dissemos anteriormente, se o ato de pensar é parcial ou implicado, é porque ele é produzido nos encontros involuntários experimentados por cada indivíduo em seu próprio trajeto. Sendo assim, o mesmo signo pode violentar duas pessoas de forma completamente diferente, visto que o sentido atribuído a essa violência dependerá em parte do próprio movimento ou percurso que cada uma delas está traçando.

Pois bem, poderíamos dizer que a essência ou ideia de um signo dependerá também, parcialmente, desse encontro, porém de outro modo. Deleuze considera que as essências fazem parte do que ele denomina de séries e, mais ainda, de grupos: isso significa dizer que um mesmo signo pode estar associado a diferentes essências ou ideias, que serão atingidas ou selecionadas de acordo com os encontros particulares de cada indivíduo. ${ }^{7}$ 
De início, um signo se apresenta num percurso como fazendo parte de um grupo mais genérico, do qual ainda se desconhece sua essência. É a partir do trabalho de criação ou tradução que se começa a individualizá-lo, a atingir sua essência. A partir disso, o signo remete a uma série, que, por sua vez, pode apresentar múltiplas variações, dependendo de qual essência tenha sido selecionada.

Devemos lembrar que essa seleção da essência é sempre involuntária, contingente, na medida em que está sujeita ao acaso dos encontros e da maneira como se é violentado pelos signos. É por isto que em determinado nível pode-se afirmar que as essências são também criadas, produzidas, já que dependem em parte dos encontros involuntários dos indivíduos e do sentido que cada um deles conseguirá traduzir.

É necessário ressaltar, entretanto, que as essências ou ideias não dependem do sujeito, somente sua seleção, e mesmo esta seleção é feita de forma involuntária. É como se as essências constituíssem uma realidade superior, ao estilo platônico. No entanto, o fato de uma essência ou ideia poder ser selecionada entre várias em um grupo de signos, ainda que de forma involuntária, é justamente o que vai diferenciar o conceito de essência desenvolvido por Platão, do conceito de essência desenvolvido por Deleuze na obra sobre Proust. Afinal, como já vimos na primeira parte de nosso trabalho, a essência platônica diz respeito a uma identidade. Já o conceito de essência, tal como aparece em Proust e os signos, diz respeito, ao contrário, à diferença.

Em Platão, a essência é aquilo que permanece idêntica a si mesma. Por isso mesmo, o filósofo ou qualquer outra pessoa, desde que utilizando o pensamento da forma correta, poderia atingir a essência imutável de algum conceito, objeto ou mesmo do próprio mundo. Em outras palavras, a essência, por ser idêntica a si própria, nos asseguraria atingir as verdades universais, as verdades invariáveis que deveriam ser objeto de uma recognição por todos. Re-cognição ou re-conhecimento, já que as coisas possuiriam uma natureza à priori.

Por outro lado, em Proust e os signos, a essência é objeto de uma seleção: ela é variável de acordo com os encontros que se tem com os signos, encontros que violentarão cada sujeito de forma particular. A essência aqui ainda é um ponto de vista ou uma ideia superior, mas somente porque através dela o artista atinge (produz) uma verdade sobre si próprio e o mundo, uma verdade parcial, implicada, advinda do seu próprio modo de viver. É por este motivo que Deleuze dirá que a essência é individualizante, ou seja, ela produz diferenças e não universalidades.

É por isso também que dissemos anteriormente que somente em certo nível as essências são criadas ou produzidas. A opção pelo termo "criar" foi somente uma tentativa de ressaltar a diferença existente entre o conceito de essência tal como é utilizado por Platão e como é utilizado por Deleuze em Proust e os signos: se, por um lado, a essência platônica denota uma identidade, visto que somente poderia haver uma essência, uma verdade para cada coisa, em Deleuze, a essência comporta uma variação, uma seleção. 
Sendo assim, não se pode apressadamente entender que as essências são criadas a fim de que elas sejam fabricadas pelos indivíduos. Na verdade, são elas que criam ou selecionam estes últimos. Elas constituem mundos que preexistem aos indivíduos e que serão vivenciados pelos mesmos. Ao final de um percurso, são as essências que "explicam" o sujeito, singularizando-o. É por meio delas que cada um atinge os mundos que os constituem, que se vai, pouco a pouco, se inventando ou produzindo, ou ainda, "descobrindo" as verdades implicadas que concernem somente à própria trajetória ou percurso singular. $\mathrm{O}$ conceito de essência em Deleuze expressa na verdade um processo de diferenciação.

Cada sujeito exprime o mundo de um certo ponto de vista. Mas o ponto de vista é a própria diferença, a diferença interna e absoluta. Cada sujeito exprime, pois, um mundo absolutamente diferente e, sem dúvida, o mundo expresso não existe fora do sujeito que o exprime (o que chamamos de mundo exterior é apenas a projeção ilusória, o limite uniformizante de todos esses mundos expressos). Mas o mundo expresso não se confunde com o sujeito: dele se distingue exatamente como a essência se distingue da existência e inclusive de sua própria existência. Ele não existe fora do sujeito que o exprime, mas é expresso como a essência, não do próprio sujeito, mas do Ser, ou da região do Ser que se revela ao sujeito (DELEUZE, 2006, p. 40-41).

Resta explicar, entretanto, de que modo é possível atingir esses mundos ou essências, através dos quais seria possível alcançar ou produzir verdades singulares. Deleuze nos aponta a resposta: por meio do estilo. Na opinião do filósofo francês, o estilo é o modo através do qual se traduz ou se interpreta os diferentes signos dos encontros. É o estilo de cada um que será responsável por selecionar as essências, e de uma forma completamente paradoxal: pois, se as essências são selecionadas de forma involuntária, significa dizer que de início desconhece-se o próprio estilo. Este será revelado, passo a passo, por meio das essências. O estilo seleciona as essências, mas estas por sua vez selecionam o estilo. É por isto que da perspectiva do filósofo francês a busca da verdade é sempre objeto de um aprendizado involuntário. De início, há um desconhecimento do próprio estilo, das próprias verdades. São as essências, os mundos, os diversos pontos de vista que atravessam um sujeito e o singularizam que acabam por revelar o seu estilo.

Assim, por meio de Proust e os signos, Deleuze nos apresenta outra imagem do pensamento distante da imagem representacional: a da imanência ou do devir pensador. Ele nos mostra como este pensador-artista vai aos poucos se constituindo, ou seja, vai se individualizando através dos encontros experimentados em seu trajeto. Mais ainda, o filósofo francês nos mostra que a obra - artística, filosófica etc. - diz respeito, na verdade, ao viver. Quadros, escritos, esculturas não passam de obras que exprimem o estilo de uma obra maior. O artista ou o pensador filósofo é aquele que em seu viver inventa a própria vida e seu próprio estilo, que "descobre" essências e verdades. Cria por meio do viver e de seu estilo, através dos encontros com os signos, seu modo singular de existir, mas só 
alcançado ao final de um longo trajeto de aprendizagem: $O$ tempo redescoberto ou "A vida como obra de arte" (DELEUZE, 1983, 2007b), como nos diz o título de uma entrevista de Deleuze acerca do pensador Michel Foucault, ou ainda uma "Estética da existência" (FOUCAULT, 2006[1984]), citando o título de uma entrevista do próprio historiador francês.

\section{Notas}

${ }^{1}$ Em Lógica do sentido (DELEUZE, 2007c, p.130), encontramos: "Quando perguntamos 'que é orientar-se no pensamento', aparece que o pensamento pressupõe ele próprio eixos e orientações segundo as quais se desenvolve, que tem uma geografia antes de ter uma história, que traça dimensões antes de construir sistemas".

${ }^{2}$ Acerca da produção filosófica e das diferenças desta em relação à produção científica e artística, ver O que é a filosofia (DELEUZE; GUATTARI, 2007), escrito em parceria com Félix Guattari.

${ }^{3} \mathrm{Em}$ Diferença e repetição, mais especificamente no capítulo denominado "A imagem do pensamento" (DELEUZE, 2009b), podemos encontrar os principais pressupostos do modelo da representação, bem como suas correlações com a imagem moral do pensamento.

${ }^{4}$ Em sua Microfísica das criações parciais (MANGUEIRA, 2001, p. 81-82), Maurício Mangueira nos aponta de que modo na obra de pensadores como Friedrich Nietzsche e Gilles Deleuze já podemos encontrar uma problemática que diz respeito à oposição entre duas formas de exercício do pensamento. A partir disso, o autor estabelece uma diferença entre dois tipos de pensamento: um pensamento teórico-representacional, que visa o conhecimento e o estabelecimento de verdades universais; e um pensamento que o autor denomina de criador-proximal ou imanente, pensamento que se encontra implicado em um dado território existencial e que busca afirmar a si próprio, caracterizando-se justamente pela efetivação de uma potência criadora.

${ }^{5}$ Acerca do papel representacional do signo, ver As palavras e as coisas (FOUCAULT, 2007), mais especificamente o capítulo III, intitulado "Representar". Nele, Foucault demonstra de que forma a produção de conhecimento no período Clássico se encontrava profundamente correlacionada a uma ciência da ordem ou Máthêsis. O traço característico dessa Máthêsis era justamente estabelecer relações de identidade entre as coisas por meio do signo, sendo que este surgia assim para assinalar uma relação de representação. Por conta disso, o historiador francês dirá que a principal característica assumida pelo signo nesse período é a "representação reduplicada", característica que continuará presente no pensamento moderno.

${ }^{6} \mathrm{Na}$ primeira parte de Proust e os signos (DELEUZE, 2006), Deleuze discorre acerca dos diversos tipos de signos presentes na obra de Proust e de como eles constituem sistemas de mútua ressonância e afetação entre si.

${ }^{7}$ A questão das séries e dos grupos pode ser encontrada no capítulo VI de Proust e os signos.

\section{REFERÊNCIAS}

DELEUZE, G. O tempo redescoberto. Porto Alegre: Globo, 1983.

DELEUZE, G. Proust e os signos. Rio de Janeiro: Forense Universitária, 2006.

DELEUZE, G. Platão e o Simulacro. In: . Lógica do Sentido. São Paulo: Perspectiva, 2007a. p. 259-271.

DELEUZE, G. A vida como obra de arte. In: . Conversações. São Paulo: Editora 34, 2007b. p. 118-126.

DELEUZE, G. Lógica do Sentido. São Paulo: Editora perspectiva, 2007c.

DELEUZE, G. Diferença e repetição. São Paulo: Graal, 2009a. 
DELEUZE, G. A imagem do pensamento. In: . Diferença e repetição. São Paulo: Graal, 2009b. p.189-240.

DELEUZE, G.; GUATTARI, F. O Que é a Filosofia. São Paulo: Editora 34, 2007.

FOUCAULT, M. Uma estética da existência (1984). In: .Ética, sexualidade e política. Rio de Janeiro: Forense Universitária, 2006. p. 288-293. Coleção Ditos e Escritos, v. 5.

FOUCAULT, M. As palavras e as coisas. São Paulo: Martins Fontes, 2007.

MANGUEIRA, M. Microfisica das criações parciais: pensamento, subjetividade e prática a partir de Nietzsche e Deleuze. São Cristóvão: UFS, 2001.

PROUST, M. Em busca do tempo perdido. São Paulo: Companhia das Letras, 2001.

Recebido em: 06 de agosto de 2010 Aceito em: 18 de maio de 2011 